\title{
Effects of Ultrasonic Waves during Resin Impregnation on the Mechanical Properties of Unidirectional Composite Materials
}

\author{
Yasunari Kuratani ${ }^{*}$, Aya Miki ${ }^{2}$, Norimichi Nanami ${ }^{3}$, Hayato Nakatani ${ }^{4}$, Hiroyuki Hamada ${ }^{1}$ \\ ${ }^{1}$ Department of Advanced Fibro-Science, Kyoto Institute of Technology, Kyoto, Japan \\ ${ }^{2}$ General Affairs Department, KADO Corporation, Hyogo, Japan \\ ${ }^{3}$ Department of Mechanical Engineering, College of Science and Technology, Nihon University, Tokyo, Japan \\ ${ }^{4}$ Department of Mechanical \& Physical Engineering, Osaka City University, Osaka, Japan \\ Email: *kuratani@kado-corporation.com
}

How to cite this paper: Kuratani, Y., Miki, A., Nanami, N., Nakatani, H. and Hamada, H. (2018) Effects of Ultrasonic Waves during Resin Impregnation on the Mechanical Properties of Unidirectional Composite Materials. Open Journal of Composite Materials, 8, 1-10.

https://doi.org/10.4236/ojcm.2018.81001

Received: November 16, 2017

Accepted: December 15, 2017

Published: December 18, 2017

Copyright $\odot 2018$ by authors and Scientific Research Publishing Inc. This work is licensed under the Creative Commons Attribution International License (CC BY 4.0).

http://creativecommons.org/licenses/by/4.0/

\section{(c) (i) Open Access}

\begin{abstract}
Effects of ultrasonic vibrations on mechanical properties of fiber reinforced plastics were investigated during molding resin impregnation process in vacuum assisted resin transfer molding. The vacuum bag including the preformed each non-crimp fabrics (carbon and glass fibers) was placed in a water bath of an ultrasonic wave generator during resin impregnation. The mechanical properties of the laminates were evaluated through the mechanical strength tests and scanning electron microscope (SEM) observation. The results revealed that ultrasonic waves improved transverse tensile, flexural, interlaminar shear, and compressive strengths of the carbon fiber (CF) laminates and interlaminar shear and compressive strengths of the glass fiber (GF) laminates. It was found from SEM observation that the fracture modes of the $\mathrm{CF}$ and GF laminates processed using ultrasonic waves were resin fracture. Accordingly, the adhesion of the fiber/resin interface was improved by oscillating ultrasonic vibration during resin impregnation, leading to an increase of the interface strength.
\end{abstract}

\section{Keywords}

Carbon Fiber Reinforced Plastics, Glass Fiber Reinforced Plastics, Non-Crimp Fabrics, Vacuum Assisted Resin Transfer Molding, Mechanical Strength, Ultrasonic Wave, Interfacial Debonding

\section{Introduction}

In recent years, carbon dioxide emissions reduction and resource saving are demanded to preserve the global environment. Since reducing weights of trans- 
portation equipment such as aircrafts and automobiles results in the improvement of its fuel efficiency, the performance improvement of lightweight structural materials with high strength is required. In particular, the application of carbon fiber reinforced plastics (CFRP) with lightweight and high strength increases in composite materials utilized in the aerospace industry [1] [2]. One of the major molding methods of CFRP is the vacuum assisted resin transfer molding (VaRTM) method, and it is a reliable low-cost manufacturing process. Since the method does not require the use of prepregs and autoclaves, it can save on a lot of expanse for intermediate materials and manufacturing equipment. Additionally, large-size structural components can be integrally molded by the method, leading to a reduction in the number of parts [3]. However, the method using thermoset resin needs an oven or another simple heating method to cure resin impregnated with fibers. In the previous study, the influences of external and internal heating in the curing process to the mechanical properties of fiber reinforced plastics (FRP) were investigated using the same materials and molding process [4]. While external heating was defined as heating the base material by hot air generated in an oven, internal heating indicated that the base material was heated by self-generated heat of fibers. The study revealed that external heating improved the tensile strength of FRP laminates in the transverse $\left(90^{\circ}\right)$ direction [4]. The studies on the heating methods using microwaves and near infrared waves in the curing process have been conducted [5] [6]. However, the relationship between a molding process and the mechanical properties of molded products is not investigated and assessed in the studies. Also, there are no precedent reports on mechanical properties of FRP laminates processed by a conventional FRP molding process in applying of ultrasonic waves. In this study, the effects of ultrasonic waves using an ultrasonic generator during resin impregnation on the mechanical properties of FRP laminates were investigated in the VaRTM process. The laminates were processed using ultrasonic waves and not using them. The mechanical strength testing of the laminates was performed to discuss the effectivity and advantages of ultrasonic waves in the curing process of the VaRTM method.

\section{Experiment Method}

\subsection{Material}

Two kinds of non-crimp fabrics (NCF) as base materials, carbon fibers (CF) and glass fibers (GF), were employed for this study. A dry NCF of unidirectional (UD) CF coated with epoxy powders (an areal weight of $324 \mathrm{~g} / \mathrm{m}^{2}$ ) was supplied by SAERTEX GmbH \& Co. KG. A dry NCF of UD-GF (an areal weight of 677 $\mathrm{g} / \mathrm{m}^{2}$ ) was produced by SHINDO Co. Ltd. The two-part epoxy resin supplied by AXSON Technologies was employed as base materials. Its mixing ratio by weight between the main agent and cure agent is preferably 100:30.

\subsection{Molding Method with Ultrasonic Waves}

The configuration of the laminates processed by the VaRTM method is shown in 
Table 1. The shape of all laminates was rectangular, and their fiber orientation was $0^{\circ}$. For accomplishing approximately $2 \mathrm{~mm}$ in laminate thickness, the CF laminates consisted of six plies of CF NCF, and the GF laminates were composed of four plies of GF NCF.

In the VaRTM process, the fiber base materials were laminated based on the laminate configuration. The preformed fiber base materials in a rectangular shape were covered with a vacuum bag. The vacuum bags were placed in a water bath of the ultrasonic wave generator as shown in Figure 1. In the laminates 1 and 3, both the ambient temperature and the water temperature were kept at $25^{\circ} \mathrm{C}$ during resin injection. Ultrasonic waves continued to oscillate until the resin was impregnated in the base material. Although the environment condition of the resin injection for the laminates 2 and 4 was identical to those for the laminates 1 and 3, the laminates 2 and 4 were processed without oscillating ultrasonic waves. After finishing of resin injection, all vacuum bags were taken out from the water bath of the ultrasonic generator. The primary curing was carried out at $25^{\circ} \mathrm{C}$ for 12 hours, and the second full cure process was performed in an oven at $50^{\circ} \mathrm{C}$ for 2 hours. All laminates were cut to prepare specimens for mechanical strength testing.

\section{Evaluation Methods}

The weight percentages of fibers a laminate, $W_{f}$ after molding was calculated as expressed in Equation (1).

$$
W_{f}=\left(M_{f}\right) /\left(M_{f}+M_{m}\right) .
$$

Here, $M_{f}$ and $M_{m}$ are masses of fiber and the resin, respectively. The CFRP laminates processed with and without ultrasonic waves had $W_{f}=81 \%$. On the other hand, the GFRP laminates processed with and without ultrasonic waves contained $W_{f}=93 \%$ and $W_{f}=91 \%$, respectively. It was confirmed that the difference in the amount of impregnated resin due to the presence or absence of the ultrasonic waves was not exhibited. The test specimens were cut out from the laminates to sizes suitable for mechanical strength testing, which were transverse $\left(90^{\circ}\right)$ tensile, three-point bending, interlaminar shear, and axial $\left(0^{\circ}\right)$ compression tests as summarized in Table 2. The fracture surface of a specimen after a transverse tensile test was observed with a scanning electron microscope (SEM).

Table 1. Laminate configuration.

\begin{tabular}{ccccc}
\hline Laminate No. & Ultrasonic Waves & Fiber Fabric & Stacking Sequence & Thickness (mm) \\
\hline 1 & Yes & CF & {$[0] 6$} & 1.92 \\
2 & No & & & \\
3 & Yes & GF & {$[0] 4$} & 2.32 \\
4 & No & & & \\
\hline
\end{tabular}


Table 2. Specimens for mechanical strength testing.

\begin{tabular}{|c|c|c|}
\hline Fiber Fabric & Ultrasonic Waves & Test \\
\hline \multirow{3}{*}{$\mathrm{CF}$} & Yes & \multirow{5}{*}{ Tensile test } \\
\hline & No & \\
\hline & & \\
\hline \multirow{2}{*}{ GF } & Yes & \\
\hline & No & \\
\hline \multirow{2}{*}{$\mathrm{CF}$} & Yes & \multirow{5}{*}{ 3-points Bending Test } \\
\hline & No & \\
\hline \multirow{3}{*}{ GF } & & \\
\hline & Yes & \\
\hline & No & \\
\hline \multirow{2}{*}{$\mathrm{CF}$} & Yes & \multirow{5}{*}{ Interlaminar Shear Test } \\
\hline & No & \\
\hline \multirow{3}{*}{ GF } & Yes & \\
\hline & & \\
\hline & & \\
\hline \multirow{2}{*}{$\mathrm{CF}$} & Yes & \multirow{5}{*}{ Compression Test } \\
\hline & No & \\
\hline \multirow{3}{*}{ GF } & & \\
\hline & Yes & \\
\hline & No & \\
\hline
\end{tabular}

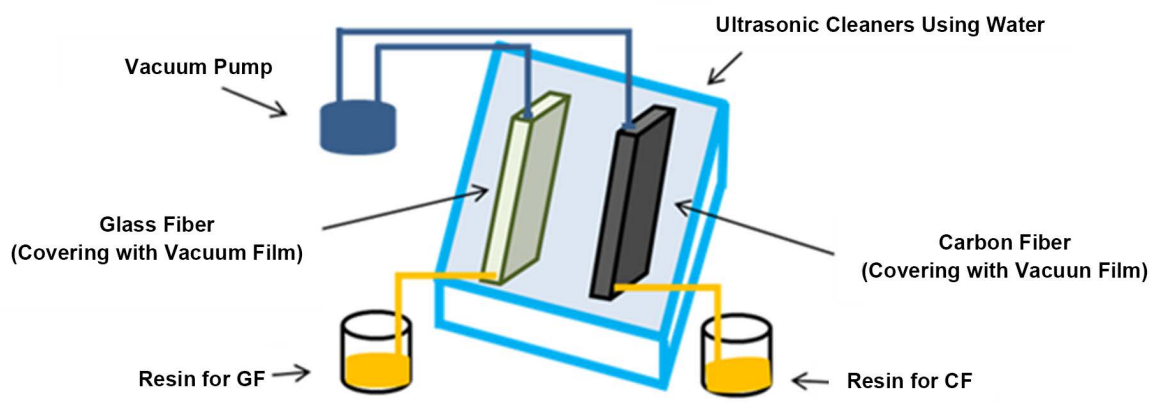

Figure 1. The schematic of resin injection in the water bath of the ultrasonic wave generator.

\subsection{Tensile Test (JIS K 7165)}

The size of the tensile test specimen was a coupon shape of $100 \mathrm{~mm}$ in length $\mathrm{x}$ $10 \mathrm{~mm}$ in width. Note that the fiber direction of the specimens was vertical to the tensile loading direction to evaluate the transverse tensile strength of the laminate. Grip portions of the specimen were $20 \mathrm{~mm}$ measured from both ends of the specimen, and the gauge length was $60 \mathrm{~mm}$. The other conditions were conducted according to JIS K7165 [7]. The universal testing machine (Autograph AG-I: SHIMADZU CORPORATION) was employed to apply a tensile load to a specimen at the crosshead displacement speed of $1 \mathrm{~mm} / \mathrm{min}$ until it failed. A strain gauge (KFGS-2-120-D16-11: Kyowa Electronic Instruments Co., Ltd.) was attached to the surface of a specimen, and the strain was recorded during a tensile 
test. Though the number of tensile specimens was five, the specimens with the maximum and the minimum values of the strength were excluded from the idea of dispersion error, and tensile strength of the laminate was obtained from three specimens.

\subsection{Three-Point Bending Test (JIS K 7074)}

The size of the bending test specimen was a coupon shape of $100 \mathrm{~mm}$ in length $\mathrm{x}$ $15 \mathrm{~mm}$ in width. Note that the fiber direction of the specimen $\left(0^{\circ}\right)$ was aligned with the length direction of the specimen. The distance between two supporting pins was $80 \mathrm{~mm}$, and the other conditions were conducted according to JIS K7074 [8]. The universal testing machine (Autograph AG-I: SHIMADZU CORPORATION) was employed, and a bending load was applied at a crosshead displacement speed of $5 \mathrm{~mm} / \mathrm{min}$. In spite of preparation of seven bending specimens, two specimens with the maximum and minimum bending loads were excluded upon finding the flexural strengths of the laminates. Thus, the flexural strength of the laminates was found at $\mathrm{N}=5$.

\subsection{Interlaminar Shear Test (JIS K 7078/JIS K 7057)}

The interlaminar shear tests of the CF and GF specimens were performed according to JIS K 7078 [9] and JIS K 7057 [10], respectively. The size of the CF specimen was a coupon shape of $14 \mathrm{~mm}$ in length $\times 10 \mathrm{~mm}$ in width. The size of the GF specimen was a coupon shape of $20 \mathrm{~mm}$ in length $\times 10 \mathrm{~mm}$ in width. The universal testing machine (RTC-1350A: ORIENTEC CORPORATION) was utilized for the interlaminar shear tests of the CF and GF specimens. The distance between two supporting pins was $10 \mathrm{~mm}$. The number of the specimens was $\mathrm{N}=$ 3. A load was applied at a crosshead displacement speed of $1 \mathrm{~mm} / \mathrm{min}$.

\subsection{Compression Test (JIS K 7018)}

The size of the compression test specimen was a coupon shape of $110 \mathrm{~mm}$ in length $\times 10 \mathrm{~mm}$ in width. The distance between terminal tabs was $10 \mathrm{~mm}$, and the terminal tab had a length of $50 \mathrm{~mm}$. The other conditions were conducted according to JIS K7018 [11]. A compressive load was applied a crosshead displacement speed of $1 \mathrm{~mm} / \mathrm{min}$ using the universal testing machine (RTC-1350A: ORIENTEC CORPORATION). A strain gauge (KFGS-10-120-C1-11: Kyowa Electronic Instruments Co., Ltd.) was attached to the surface of the specimen, and a compressive strain was recorded during the compression test. The number of the specimens was $\mathrm{N}=3$.

\subsection{Observation of Fracture Surface}

The fracture surface of the specimen after the tensile test described in Section 3.1 was observed using a SEM (JSM-5200: JEOL Ltd.). The sample preparation process is as follows: The specimen after the test was cut to a height of $4 \mathrm{~mm}$, and it was attached to a cast-iron cylinder of $10 \mathrm{~mm}$ in diameter with a carbon 
tape. Afterward, the ion sputtering was performed in a vacuum of $10 \mathrm{~Pa}$ by a two-pole sputtering method. The magnifications of the microscope were factors of 35 and 750.

\section{Experiment Results}

\subsection{Carbon Fiber Fabrics}

The results for four kinds of the mechanical strength tests are summarized in Figure 2. The strength ratios of the CF specimen with presence of ultrasonic to the CF specimens with absence of ultrasonic waves are shown in Table 3. The CF specimens with ultrasonic waves were higher in four kinds of the strengths than those without ultrasonic waves. Since the tensile test showed the most difference in strength among four kinds of the tests, the fracture surface of the tensile specimen was observed by SEM as shown in Figure 3. While no significant differences in failure mode were seen at a magnification of $\times 35$, the differences became clear by a magnification of $\times 750$. Generally, the fracture mode of interfacial debonding means a factor of inhibiting adhesion exists in an interfacial surface. Matrix does not remain on the surface of no fibers. Thus this dominant fracture mode of the CF specimens without ultrasonic waves was interfacial debonding of the fiber/resin interface. On the other hand, the fracture mode of resin fracture means a factor of inhibiting adhesion exists in matrix. In this mode, the adhesion of resin is observed on the fibers. It was found that the dominant fracture mode of the $\mathrm{CF}$ specimen with ultrasonic waves was resin fracture rather than interfacial debonding.

\subsection{Glass Fiber Fabrics}

The results for four kinds of the tests are summarized in Figure 4, and the strength ratios of the GF specimen with presence of ultrasonic to the GF specimens with absence of ultrasonic waves are shown in Table 3. The GF specimens with ultrasonic waves showed higher interlaminar shear and compressive strengths than those without ultrasonic waves. However, the tensile and flexural strengths of the GF specimens without ultrasonic waves were higher in comparison to the GF specimens with ultrasonic waves. The fracture surface of the tensile test specimen was observed by SEM as shown in Figure 5. The GF specimens with ultrasonic waves did not fracture completely. Since the specimens were still connected partly after the tensile test, they were pulled manually for SEM observation of the fracture surface. The lower part (framed in red) at a

Table 3. Strength comparison between the specimen with and without ultrasonic waves.

\begin{tabular}{ccccc}
\hline Fiber Fabric & Tensile strength & Flexural strength & $\begin{array}{c}\text { Interlaminar shear } \\
\text { strength }\end{array}$ & $\begin{array}{c}\text { Compressive } \\
\text { strength }\end{array}$ \\
\hline CF & $8.7 \%$ & $1.8 \%$ & $2.1 \%$ & $4.6 \%$ \\
GF & $-19.0 \%$ & $-4.4 \%$ & $2.8 \%$ & $0.8 \%$
\end{tabular}



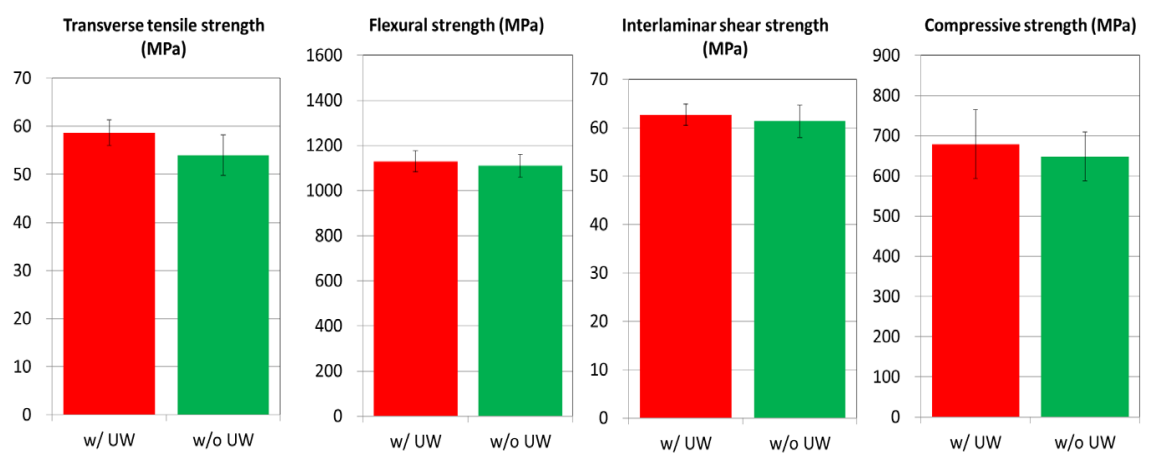

Figure 2. Mechanical strengths of CF specimens.

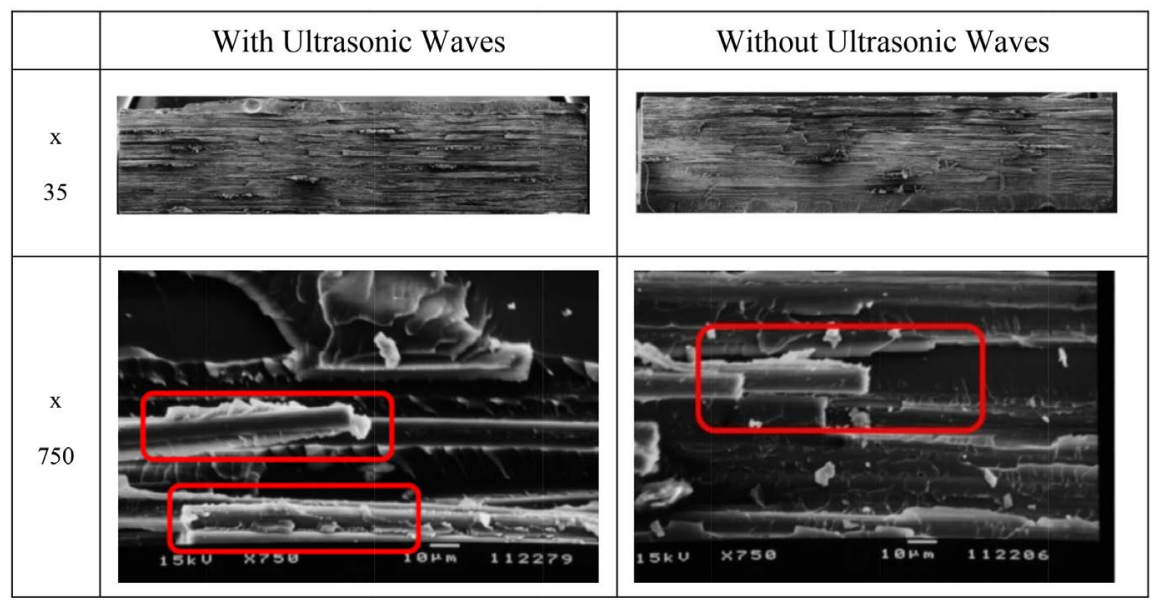

Figure 3. SEM images of the CF specimens.
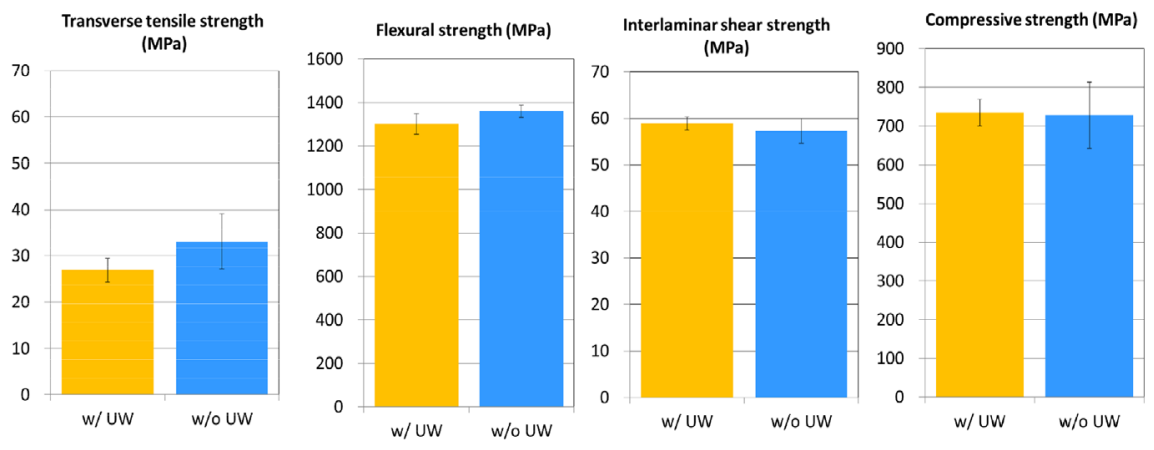

Figure 4. Mechanical strengths of GF specimens.

magnification of $\times 35$ in Figure 5 was indicated tensile fracture caused by the testing machine. Additionally, fiber fracture was not observed, and a high possibility of debonding between fibers and resin was found. The fracture surface of the specimen was observed at a magnification of $\times 750$ to capture its details. Resin fracture was observed rather than interfacial debonding as the dominant fracture mode of the GF specimen with ultrasonic waves. On the other hand, it was found that the dominant fracture mode of the GF specimen without ultrasonic waves was interfacial debonding of the fiber/resin interface. 


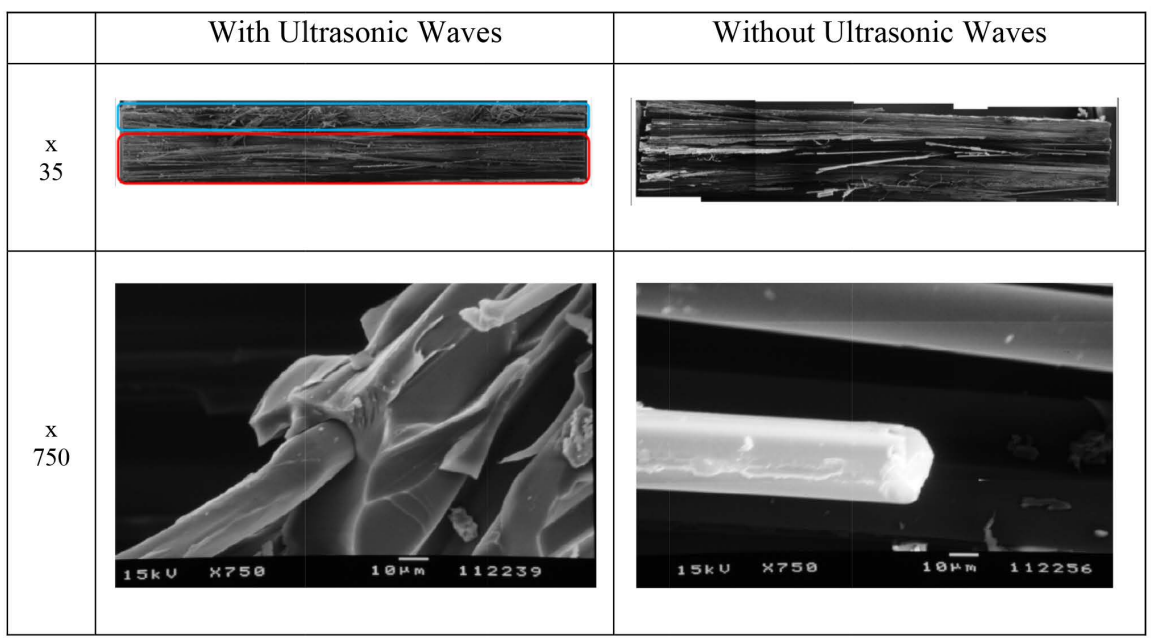

Figure 5. SEM images of the GF specimens.

\section{Discussion}

\subsection{Carbon Fiber Fabrics}

It was shown ultrasonic waves improved transverse tensile, flexural, interlaminar shear, and compressive strengths of CF specimens. Since there were no differences in weight fraction of fiber regardless of the presence and absence of ultrasonic waves, the condition to improve the strengths were identical between the CF specimens with and without ultrasonic waves. Since the difference in transverse tensile strength was $8.7 \%$ and was remarkable, the dominant fracture mode was found from SEM observation. Resin fracture was presented in the CF specimen with ultrasonic waves. Therefore, oscillating ultrasonic vibration during resin impregnation induced the improvement of the adhesion at the fiber/resin interface. Since this led to increasing the interface strength of the CF specimens, the failure mode of the CF laminate was switched the interfacial debonding to resin fracture, and its transverse tensile strength with ultrasonic waves was increased.

\subsection{Glass Fiber Fabrics}

Ultrasonic waves in the resin impregnation of the GF specimens were apt to improve interlaminar shear and compressive strengths. Since the difference in weight fraction of fiber generated by the presence and absence of ultrasonic waves was $2 \%$, the difference did not significantly make an impact on the strengths.

The SEM observation of the specimen after the tensile test showed that the GF specimen without ultrasonic waves failed due to interfacial debonding of the fiber/resin interface while resin fracture occurred in the GF specimen with ultrasonic waves. Therefore, the adhesion of the fiber/resin interface was improved by ultrasonic vibration although the transverse tensile strength of the GF specimens without ultrasonic waves was higher. Consequently, the study revealed that oscillating ultrasonic waves on CF and GF laminates was effective at the fiber/ 
resin interface.

The characteristics of the tensile and flexural strengths conflicted between the $\mathrm{CF}$ and GF specimens. The reason for these characteristics was because the ultrasonic wave caused a change in the balance between the interfacial strength of the fiber/matrix resin and the strength of resin. The change of the balance for $\mathrm{CF} /$ epoxy was different to that for GF/epoxy. In addition, the number of the test specimens needs to be increased since the influence of fiber waviness is conceivable.

\section{Conclusions}

Dry non-crimp fabrics of unidirectional carbon and glass fibers were prepared and preformed to fabricate the laminates by the VaRTM method. The vacuum bag including the preformed non-crimp fabrics was placed in the water bath of the ultrasonic wave generator during resin impregnation. The mechanical properties of the laminates were evaluated to investigate the effects of ultrasonic waves during resin impregnation on the CF and GF laminates through the mechanical strength tests and SEM observation.

Ultrasonic waves induced increases of transverse tensile, flexural, interlaminar shear, and compressive strengths of the CF laminates. The GF laminates with ultrasonic waves showed higher interlaminar shear and compressive strengths than the GF laminate without ultrasonic waves. The effects of ultrasonic waves on mechanical strength were not seen for the GF laminates, overall. It was found from SEM observation that the fracture modes of both the CF and GF laminates were not interfacial fractures of fiber/matrix but resin fracture. Accordingly, the adhesion of the fiber/resin interface was improved by oscillating ultrasonic vibration during resin impregnation, leading to an increase of the interface strength. Also, the difference in strength was associated with the strength of fiber/matrix interface and the strengths of fibers and resin.

This study will extend the processing mechanism of ultrasonic waves to FRP laminates by changing the combination of fiber fabrics and resin so as to observe the adhesion state of the difference in how the effect of ultrasonic waves appears. In addition, the interfacial adhesion test of this study's fiber/resin will be carried out, leading to the evaluation of the relationship between the mechanical properties of FRP and interfacial adhesion.

\section{References}

[1] Hull, D. and Clyne, T.W. (1996) An Introduction to Composite Materials. Cambridge University Press, Cambridge. https://doi.org/10.1017/CBO9781139170130

[2] Suemasu, H. (2009) Mechanics of Composite Materials Introduction to Engineering Beginners. BAIFUKAN CO., LTD., Tokyo.

[3] Nagao, Y. (2007) Development of People-Friendly Passenger Aircraft. http://www.jaxa.jp/article/interview/vol30/p3_j.html

[4] Kuratani, Y., Hase, K., Kawazu, T., Miki,A., Goto, A., Uozumi, T. and Hamada, H. (2016) Analysis of Mechanical Property in the Difference of Worker's Skill and 
Curing Process. The 13th International Conference on Flow Processing in Composite Materials, Kyoto, 6-9 September 2016, Paper ID 44.

[5] Sloan, J. (2011) Microwave: An Alternative to the Autoclave? https://www.compositesworld.com/articles/microwave-an-alternative-to-the-autocl ave

[6] Tanaka, K. and Yamamoto, K. (2007) Study on Curing Reaction of Thermosetting Resins by Microwave Processing. Journal of Network Polymer, Japan, 28, 87-92.

[7] Japanese Standards Association (2014) Plastics Determination of Tensile Properties. JIS K 7165:2008.

[8] Japanese Standards Association (2014) Testing Methods for Flexural Properties of Carbon Fiber Reinforced Plastics. JIS K 7074:1988.

[9] Japanese Standards Association (2014) Testing Method for Apparent Interlaminar Shear Strength of Carbon Fiber Reinforced Plastics by Three Point Loading Method. JIS K 7078:1991.

[10] Japanese Standards Association (2014) Fibre-Reinforced Plastic CompositesDetermination of Apparent Interlaminar Shear Strength by Short-Beam Method. JIS K 7057:2006.

[11] Japanese Standards Association (2014) Fiber-Reinforced Plastic CompositesDetermination of Compressive Properties in the In-Plane Direction. JIS K 7018:1999. 